\title{
Antimicrobial activities of extracts from Urtica urens
}

\author{
${ }^{1 *}$ Pillai, M.K., ${ }^{1}$ Matamane, R.P. and ${ }^{2}$ Mekbib, S.B. \\ ${ }^{1}$ Department of Chemistry and Chemical Technology, Faculty of Science and Technology, National \\ University of Lesotho, Roma Campus, P. O. Roma 180, Kingdom of Lesotho, Southern Africa \\ ${ }^{2}$ Department of Biology, Faculty of Science and Technology, National University of Lesotho, Roma Campus, \\ P. O. Roma 180, Kingdom of Lesotho, Southern Africa
}

\begin{abstract}
Article history:
Received: 26 February 2020

Received in revised form: 28

March 2020

Accepted: 1 April 2020

Available Online: 19 March 2020
\end{abstract}

\section{Keywords:}

Urtica urens,

Urticaceae,

Antibacterial activity,

Antifungal activity,

Agar hole-plate diffusion

assay

DOI:

https://doi.org/10.26656/fr.2017.4(5).088

\begin{abstract}
The antibacterial and antifungal activities of various extracts from Urtica urens were evaluated against selected microorganisms using agar hole-plate diffusion method. A total of ten extracts namely $U$. urens hexane leaf extract (HLE), chloroform leaf extract (CLE), ethyl acetate leaf extract (ELE), methanolic leaf extract (MLE), hexane stem-bark extract (HSB), chloroform stem-bark extract (CSB), ethyl acetate stem-bark extract (ESB), methanolic stem-bark extract (MSB), chloroform root extract (CRT) and methanolic root extract (MRT) were prepared. These extracts were evaluated against two Gram-positive bacteria viz. Listeria monocytogenes and Staphylococcus aureus, four Gram-negative bacteria viz. Serratia marcescens, Pseudomonas aeruginosa, Escherichia coli (wild strain) and Escherichia coli (O157:H7) and two fungal isolates viz. Candida albicans and Penicillium digitatum. The inhibition zones of these extracts were found to be in the range of $9.0 \pm 0.0$ to $40.5 \pm 0.7 \mathrm{~mm}$ against bacterial isolates and $16.0 \pm 4.2$ to $17.5 \pm 4.9 \mathrm{~mm}$ against C. albicans. However, all these extracts exhibited no visible zone of inhibition against $P$. digitatum. Additionally, the minimum inhibitory concentrations (MICs) of these extracts were also determined and were found to be in the range of $<31.25$ to $>1000 \mu \mathrm{g} / \mathrm{mL}$ against both bacterial and fungal isolates. From this study, we concluded that ELS, MLE, CRT and MRT showed promising antimicrobial activities.
\end{abstract}

\section{Introduction}

Urtica urens belongs to the Urticaceae family of the Urtica genus (Schellman et al., 2008; Nencu et al., 2015; Lati et al., 2017). It is also known by other names such as small nettle, dwarf nettle and burning nettle. U. urens is native to Mediterranean Europe. It is herbaceous shrub and grows to $75 \mathrm{~cm}$ height (Moteetee and Kose, 2017; Coleman et al., 2018). U. urens commonly found in moist soils composed of high organic matter (Coleman et al., 2018).In Southern Africa, U. urens has widely been consumed by Basotho tribes during spring season. $U$. urens has also widely been used as a traditional medicine around the world to treat anemia, asthma, rheumatism and arthritis, diabetic mellitus, heart problems, ulcers and pulmonary tuberculosis (Moteetee and Van Wyk, 2011; Barkaoui et al., 2017). U. urens is rich in phenolics, terpenoids, carotenoids and fatty acids. (El-Seadawy et al., 2018; Kregiel et al. 2018). The leaves of U. urens contains vitamins D, C and E (Mzid et al., 2017). The antimicrobial activity of chloroform, ethanolic and aqueous extracts from leaves of $U$. urens collected in Tunisia and Eritrea have previously been reported (Kaushik et al., 2015; Barkaoui et al., 2017; Mzid et al., 2017). However, our literature search showed that this plant has not been explored well for its biological and pharmacological studies, particularly, the species gathered from the Kingdom of Lesotho. The objective of the current study was to evaluate the antibacterial and antifungal activities of hexane, chloroform, ethyl acetate and methanolic extracts from leaves, stem-bark and root of $U$. urens collected from the Kingdom of Lesotho, Southern Africa.

\section{Materials and methods}

\subsection{Plant materials}

Fresh whole plants of $U$. urens were collected in October 2018 at Lithabaneng Ha Keiso and Roma village of Maseru district, Lesotho, Southern Africa. The leaves, stem-bark and root were separated from the whole plants using a pair of scissors. A voucher specimen for leaves 
(Matamane/UULE/2018), stem-bark (Matamane/ UUSB/2018) and root (Matamane/UURT/2018) were kept in the Organic Research Laboratory, Department of Chemistry and Chemical Technology, National University of Lesotho, Roma Campus, Maseru, Kingdom of Lesotho, Southern Africa.

\subsection{Processing of materials}

The air-dried plant materials were pulverized into powder using a laboratory blender (Waring Blender, Blender 80119, Model HGB2WT93, 240V AC, 3.5 AMPs, Laboratory and Analytical Supplies). Approximately, 622.01, 450.17 and $128.36 \mathrm{~g}$ of powdered leaves, stem-bark and root, respectively, were obtained.

\subsection{Preparation of plant extracts}

A total of $170.35 \mathrm{~g}$ powdered leaves were macerated with $800 \mathrm{~mL}$ of hexane for three days at room temperature with occasional agitation. The solution was filtered off using a vacuum filter (ATB, Model: 284065H, Power: 230V 3.0A, 1320/min $50 \mathrm{~Hz}$ ) and the solvent was removed by vacuo. The procedure was repeated twice. Finally, the sample was refluxed with $800 \mathrm{~mL}$ of hexane for $10 \mathrm{hr}$. Approximately, $5.12 \mathrm{~g}$ of combined hexane extract was obtained after removal of the solvent. The same procedure was repeated separately with chloroform, ethyl acetate and methanol. Approximately, $1.93,1.49$ and $3.29 \mathrm{~g}$ of chloroform, ethyl acetate and methanol leaves extracts were obtained, respectively from $150.37,150.68$ and $170.35 \mathrm{~g}$ of powdered leaves. Using similar extraction procedure, 1.12, 1.67, 1.49 and $3.29 \mathrm{~g}$ of hexane, chloroform, ethyl acetate and methanol stem-bark extracts were obtained, respectively from $99.89,99.78,100.18$ and $150.22 \mathrm{~g}$ of powdered stem bark. Similarly, 0.71 and $3.21 \mathrm{~g}$ of chloroform and methanol root extracts were obtained, respectively from 64.92 and 63.44 g powdered roots. However, we did not obtain hexane and ethyl acetate extracts from this root powder due to shortage of materials.

\subsection{Microorganisms}

Eight strains of microorganisms were used for this study. These are six bacterial isolates namely Listeria monocytogenes, Staphylococcus aureus, Serratia marcescens, Pseudomonas aeruginosa, Escherichia coli (wild strain) and Escherichia coli O157:H7 and two fungal isolates namely Penicillium digitatum and Candida albicans. All these microorganisms were obtained from the culture collection at the Department of Biology, National University of Lesotho, Roma, Kingdom of Lesotho, Southern Africa.
2.5 Evaluation of antibacterial and antifungal activities of the U. urens extracts

The antibacterial and antifungal activities of various extracts of leaf, stem-bark and root of $U$. urens were screened by in vitro agar hole-plate diffusion method as described in literature (Manilal et al., 2009; Alghazeer et al., 2012). Various extract solutions were prepared separately at a concentration of $100 \mathrm{mg}$ of extract in 1 $\mathrm{mL}$ of DMSO. The solutions were then separately filtered using $0.20 \mu \mathrm{m}$ filter and then used for both antimicrobial and antifungal activities. A $100 \mu \mathrm{L}$ of the broth culture of each bacterial strain was spread-plated on the nutrient agar (NA) plates separately. A sterile cork -borer was used to punch out $4 \mathrm{~mm}$ height and $6 \mathrm{~mm}$ diameter agar wells on the NA plates and each well was filled with $35 \mu \mathrm{L}$ aliquots of the extract. The plates were then incubated at $37^{\circ} \mathrm{C}$ for one day. Tetracycline served as positive control for E. coli (wild type), E. coli (O157:H7), S. aureus and L. monocytogenes. Amoxicillin served as positive control for $S$. marcescens and Pseudomonas aeruginosa. DMSO served as negative control. For antifungal assay, the Petri dishes filled with $20 \mathrm{~mL}$ of potato dextrose agar (PDA) were used. A total of $100 \mu \mathrm{L}$ of each fungal broth culture was spread-plated on the PDA medium. The cylindrical wells with the size of $4 \mathrm{~mm}$ height and $6 \mathrm{~mm}$ diameter were punched using an autoclaved cork-borer and then the wells were filled with $35 \mu \mathrm{L}$ aliquots of the extract. The plates were then incubated at $24^{\circ} \mathrm{C}$ for two days. Miconazole nitrate served as positive control for C. albicans and DMSO served as negative control. However, positive control was not available for $P$. digitatum. All experiments were conducted in duplicates and the results were reported as the mean of two experiments. A clear zone $>10 \mathrm{~mm}$ are considered as positive results (Lima-Filho et al., 2002). Inhibition zones of $<12,12-20$ and $\geq 20 \mathrm{~mm}$ diameter are expressed as weak, moderate and strong activities, respectively (Emmanuel et al., 2012; Matela et al., 2018).

\subsection{Determination of minimum inhibitory concentrations (MICs)}

The minimum inhibitory concentration (MIC) value refers to the minimum concentration needed to inhibit the visible growth of microorganism in a 24-hour period (Alghazeer et al., 2012; Alghazeer et al., 2017). The MIC of $<100 \mu \mathrm{g} / \mathrm{mL}, 100$ to $\leq 625 \mu \mathrm{g} / \mathrm{mL}$ and $>625 \mu \mathrm{g} /$ $\mathrm{mL}$, were considered as significantly active, moderately active and weakly active, respectively (Emmanuel et al., 2012; Njimoh et al., 2015; Alghazeer et al., 2017). The MIC values of various $U$. urens extracts were determined as described in literature (Daud et al., 2005; Alghazeer et al., 2017). Briefly, stock solutions of various extracts of 
$U$. urens was prepared separately at a concentration of $1000 \mu \mathrm{g} / \mathrm{mL}$. From each stock solution, two-fold serial dilutions of $1000,500,250,125,62.5$ and $31.25 \mu \mathrm{g} / \mathrm{mL}$ were prepared. A suspension of the microorganism is prepared at a concentration of one million to two million colony forming units $\mathrm{CFU} / \mathrm{mL}$ by means of growing the bacterial isolate in nutrient broth in an incubator with continuous agitation (Matela et al., 2018). Agar wells with the size, $4 \mathrm{~mm}$ height and $6 \mathrm{~mm}$ diameter were punched using an autoclaved cork-borer and were then filled with $35 \mu \mathrm{L}$ aliquots of the extract. The plates were incubated at $37^{\circ} \mathrm{C}$ for a period of 24 -hours.

\subsection{Statistical analysis}

Data analysis was performed using the SPSS 17.0 statistics program by means of two-way analysis of variance. The differences were considered statistically significant when $\mathrm{p} \leq 0.05$.

\section{Results and discussion}

The antimicrobial activity of various extracts from leaves, stem-bark and root of $U$. urens are summarized in Table 1. A total of ten extracts namely $U$. urens hexane leaf extract (HLE), chloroform leaf extract (CLE), ethyl acetate leaf extract (ELE), methanolic leaf extract (MLE), hexane stem-bark extract (HSB), chloroform stem-bark extract (CSB), ethyl acetate stem-bark extract (ESB), methanolic stem-bark extract (MSB), chloroform root extract (CRT) and methanolic root extract (MRT) were prepared. Against L. monocytogenes, all extracts showed a moderate activity with inhibition zones in the range of $11.5 \pm 0.7$ to $21.5 \pm 1.4 \mathrm{~mm}$ and ELE showed a significant strong activity with an inhibition zone of $21.5 \pm 1.4 \mathrm{~mm}$. The positive control, tetracycline, showed an inhibition zone of $30.5 \pm 0.7 \mathrm{~mm}$. Against $S$. aureus, all these extracts showed a weak to moderate activities with inhibition zones in the range of $11.0 \pm 1.4$ to $17.0 \pm 0.7$ $\mathrm{mm}$. The positive control, tetracycline, showed an inhibition zone of $23.5 \pm 0.7 \mathrm{~mm}$. Against $S$. marcescens, all these extracts also showed a weak to moderate activities with inhibition zones in the range of $10.5 \pm 2.1$ to $16.5 \pm 6.3 \mathrm{~mm}$. The positive control, amoxicillin, exhibited an inhibition zone of $21.5 \pm 2.1 \mathrm{~mm}$. Against $P$. aeruginosa, all these extracts showed weak to strong inhibition zones in the range of $9.5 \pm 1.4$ to $40.5 \pm 0.7 \mathrm{~mm}$. MLE, CRT and MRT exhibited significantly higher activity with inhibition zones of $22.0 \pm 2.8,21.5 \pm 0.7$ and $40.5 \pm 0.7 \mathrm{~mm}$. respectively and the remaining extracts showed a weak to moderate activities. Against E. coli (wild strain), all these extracts showed a weak to moderate activities with inhibition zones in the range of $9.0 \pm 0.0$ to $18.5 \pm 0.7 \mathrm{~mm}$. The positive control, tetracycline, showed an inhibition zone of $18.5 \pm 3.5 \mathrm{~mm}$.

Table 1. Inhibitory effect of various extracts from leaves, stem-bark and root of $U$. urens against selected microorganisms.

\begin{tabular}{|c|c|c|c|c|c|c|c|c|}
\hline \multirow[b]{3}{*}{ Extracts } & \multicolumn{8}{|c|}{ Zones of inhibition (mm) } \\
\hline & \multicolumn{2}{|c|}{ Gram-positive bacteria } & \multicolumn{4}{|c|}{ Gram-negative bacteria } & \multicolumn{2}{|c|}{ Fungal isolates } \\
\hline & $\begin{array}{l}3 \\
\vdots \\
0 \\
0 \\
0 \\
0 \\
0 \\
0 \\
0 \\
0 \\
0 \\
0\end{array}$ & 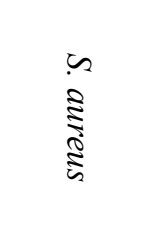 & 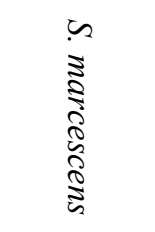 & 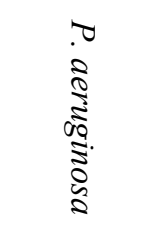 & 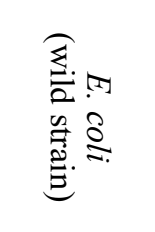 & 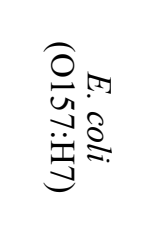 & 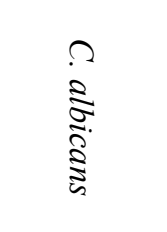 & 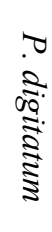 \\
\hline HLE & $15.0 \pm 4.2^{\mathrm{b}}$ & $16.5 \pm 2.1^{\mathrm{a}}$ & $12.0 \pm 4.2^{b}$ & $9.5 \pm 1.4^{\mathrm{a}}$ & $15.0 \pm 2.8^{\mathrm{a}}$ & $10.0 \pm 0.0^{\mathrm{a}}$ & $16.0 \pm 2.8^{\mathrm{a}}$ & - \\
\hline CLE & $13.5 \pm 3.3^{\mathrm{a}}$ & $10.5 \pm 2.1^{\mathrm{a}}$ & $10.5 \pm 2.1^{\mathrm{a}}$ & $18.0 \pm 2.8^{\mathrm{a}}$ & $12.0 \pm 1.4^{\mathrm{a}}$ & $13.5 \pm 3.5^{\mathrm{a}}$ & $17.0 \pm 4.2^{\mathrm{b}}$ & - \\
\hline ELE & $21.5 \pm 1.4^{\mathrm{a}}$ & $12.5 \pm 4.9^{b}$ & $11.5 \pm 3.5^{\mathrm{a}}$ & $17.0 \pm 4.2^{\mathrm{b}}$ & $13.0 \pm 1.4^{\mathrm{a}}$ & $10.5 \pm 0.7^{\mathrm{a}}$ & $17.0 \pm 7.0^{\mathrm{b}}$ & - \\
\hline MLE & $12.5 \pm 0.7^{\mathrm{a}}$ & $9.5 \pm 0.7^{\mathrm{a}}$ & $12.0 \pm 0.0^{\mathrm{a}}$ & $22.0 \pm 2.8^{\mathrm{a}}$ & $15.5 \pm 0.7^{\mathrm{a}}$ & $16.0 \pm 4.2^{b}$ & $17.0 \pm 1.4^{\mathrm{a}}$ & - \\
\hline HSB & $17.0 \pm 2.8^{\mathrm{a}}$ & $13.5 \pm 2.1^{\mathrm{a}}$ & $16.5 \pm 6.3^{b}$ & $9.5 \pm 1.4^{\mathrm{a}}$ & $16.5 \pm 6.3^{b}$ & $17.5 \pm 3.9^{\mathrm{a}}$ & $16.0 \pm 4.2^{\mathrm{b}}$ & - \\
\hline CSB & $16.5 \pm 2.1^{\mathrm{a}}$ & $11.5 \pm 2.1^{\mathrm{a}}$ & $16.0 \pm 1.4^{\mathrm{a}}$ & $12.0 \pm 1.4^{\mathrm{a}}$ & $13.0 \pm 1.4^{\mathrm{a}}$ & $12.5 \pm 2.1^{\mathrm{a}}$ & $17.0 \pm 2.8^{\mathrm{a}}$ & - \\
\hline ESB & $11.5 \pm 0.7^{\mathrm{a}}$ & $16.5 \pm 0.7^{\mathrm{a}}$ & $13.5 \pm 3.3^{\mathrm{a}}$ & $13.5 \pm 4.9^{b}$ & $18.5 \pm 0.7^{\mathrm{a}}$ & $12.5 \pm 2.1^{\mathrm{a}}$ & $17.5 \pm 4.9^{b}$ & - \\
\hline MSB & $16.0 \pm 2.8^{\mathrm{a}}$ & $11.0 \pm 1.4^{\mathrm{a}}$ & $12.5 \pm 2.1^{\mathrm{a}}$ & $14.5 \pm 0.7^{\mathrm{a}}$ & $9.0 \pm 0.0^{\mathrm{a}}$ & $10.5 \pm 1.4^{\mathrm{a}}$ & $16.5 \pm 2.1^{\mathrm{a}}$ & - \\
\hline CRT & $11.5 \pm 0.7^{\mathrm{a}}$ & $15.5 \pm 0.7^{\mathrm{a}}$ & $12.5 \pm 0.7^{\mathrm{a}}$ & $21.5 \pm 0.7^{\mathrm{a}}$ & $10.0 \pm 1.4^{\mathrm{a}}$ & $10.5 \pm 0.7^{\mathrm{a}}$ & $16.5 \pm 0.7^{\mathrm{a}}$ & - \\
\hline MRT & $11.5 \pm 0.7^{\mathrm{a}}$ & $17.0 \pm 0.7^{\mathrm{a}}$ & $13.5 \pm 2.2^{\mathrm{a}}$ & $40.5 \pm 0.7^{\mathrm{a}}$ & $16.5 \pm 2.1^{\mathrm{a}}$ & $12.5 \pm 2.1^{\mathrm{a}}$ & $17.5 \pm 3.3^{\mathrm{a}}$ & - \\
\hline Positive controls & $30.5 \pm 0.7^{\mathrm{a}}$ & $23.5 \pm 0.7^{\mathrm{a}}$ & $21.5 \pm 2.1^{\mathrm{a}}$ & $09.5 \pm 0.0^{\mathrm{a}}$ & $18.5 \pm 3.5^{\mathrm{a}}$ & $24.5 \pm 2.1^{\mathrm{a}}$ & $23.5 \pm 1.8^{\mathrm{a}}$ & \# \\
\hline
\end{tabular}

${ }^{\mathrm{a}}=$ the difference is statistically significant; ${ }^{\mathrm{b}}=$ the difference is not statistically significant.

$\mathrm{HLE}=U$. urens hexane leaf extract; CLE $=U$. urens chloroform leaf extract; $\mathrm{ELE}=U$. urens ethyl acetate leaf extracts; MLE $=$ $U$. urens methanol leaf extract; $\mathrm{HSB}=U$. urens hexane stem-bark extract; $\mathrm{CSB}=U$. urens chloroform stem-bark extract; $\mathrm{ESB}=$ $U$. urens ethyl acetate stem-bark extract; $\mathrm{MSB}=U$. urens methanol stem-bark extract; CRT $=U$. urens chloroform root extract; MRT $=U$. urens methanol root extract. Tetracycline served as a positive control against L. monocytogenes, S. aureus, E. coli (wild strain) and E. coli (O157:H7). Amoxicillin served as a positive control against $S$. marcescens and P. aeruginosa. Miconazole nitrate served as a positive control against $C$. albicans. DMSO served as a negative control. \# : No positive control used.- : No activity observed. 
Against E. coli (O157:H7), all these extracts also showed a weak to moderate activities with inhibition zones in the range of $10.0 \pm 0.0$ to $17.5 \pm 3.9 \mathrm{~mm}$. The positive control, tetracycline, showed an inhibition zone of $24.5 \pm 2.1 \mathrm{~mm}$. Against $C$. albicans, all these extracts showed a moderate activity with inhibition zones in the range of $16.0 \pm 2.8$ to $17.5 \pm 3.3 \mathrm{~mm}$. The positive control, miconazole nitrate, exhibited an inhibition zone of $23.5 \pm 1.8 \mathrm{~mm}$. We also evaluated the antifungal activity of these extracts against $P$. digitatum. However, none of the extracts showed any visible zone of inhibition against these fungal isolates.

Additionally, we also evaluated the minimum inhibitory concentration (MIC) of these extracts and the results are summarized in Table 2. Against $L$. monocytogenes, $\mathrm{HSB}, \mathrm{CSB}, \mathrm{MSB}$ and MRT were significantly active with MIC values of $62.5,62.5,62.5$ and $<31.25 \mu \mathrm{g} / \mathrm{mL}$, respectively. Other extracts showed weak to moderate activities. Against $S$. aureus, HLE was significantly active with MIC value of $62.5 \mu \mathrm{g} / \mathrm{mL}$ and all other extracts showed a weak to moderate activities. Against $S$. marcescens, CLE, CRT and MRT exhibited a significant activity with MIC values of $62.5,<31.25$ and $<31.25 \mu \mathrm{g} / \mathrm{mL}$, respectively and other extracts showed moderate activity. Against $P$. aeruginosa, HLE, ELE, HSB, CSB, ESB, CRT and MRT exhibited a significant activity with MIC values of $62.5,<31.25,62.5,<31.25$, $<31.25,<31.25$ and $62.5 \mu \mathrm{g} / \mathrm{mL}$, respectively. However, CLE, MLE and MSB exhibited moderate activity. Against E. coli (wild strain), HLE, CLE, ELE, MLE and HSB showed significant activity with MIC values of $62.5,<31.25, \quad<31.25,<31.25$ and $62.5 \mu \mathrm{g} / \mathrm{mL}$, respectively. MRT showed weak activity and CSB, ESB,
MSB and CRT showed moderate activity (refer to Table 2). Against E. coli (O157:H7), CLE and MLE exhibited a significant activity with MIC values of 62.5 and $<31.25$ $\mu \mathrm{g} / \mathrm{mL}$, respectively and all other extracts showed a moderate activity (refer to Table 2). Against C. albicans, HLE, ELE and HSB exhibited a strong activity with MIC values of $<31.25 \mu \mathrm{g} / \mathrm{mL}$, for each extract and all other extracts showed a weak to moderate activity (refer to Table 2). We did not conduct any experiment for the antifungal activity of these extracts against $P$. digitatum since these extracts did not show any visible inhibition zone in the preliminary study.

Microorganisms such as $P$. aeruginosa, S. aureus, $E$. coli and C. albicans have previously been used to screen the antimicrobial activity of chloroform, ethanol and aqueous extracts obtained from leaves of $U$. urens (Kaushik et al., 2015; Barkaoui et al., 2017; Mzid et al., 2017). The leaves have been collected at various geographic locations in Tunisia and Ethiopia. Some of these extracts exhibited remarkable antimicrobial against these microorganisms, while the others are not. However, the results obtained among these studies were not consistent, even among the same extracts (Kaushik et al., 2015; Barkaoui et al., 2017; Mzid et al., 2017). Additionally, we noticed that the chloroform extracts were common to our study also. Therefore, we have chosen the same microorganisms to compare our chloroform extracts results with previously reported results. Additionally, we also screened our other extracts namely hexane, ethyl acetate and methanol extracts against the same microorganisms. Furthermore, we have also chosen three more microorganisms namely $L$. monocytogenes, $S$. marcescens and $P$. digitatum for this

Table 2. The minimum inhibitory concentrations (MICs) of various extracts from $U$. urens on selected microorganisms.

\begin{tabular}{|c|c|c|c|c|c|c|c|c|}
\hline \multirow[b]{3}{*}{ Extracts } & \multicolumn{8}{|c|}{ Zones of inhibition (mm) } \\
\hline & \multicolumn{2}{|c|}{ Gram-positive bacteria } & \multicolumn{4}{|c|}{ Gram-negative bacteria } & \multicolumn{2}{|c|}{ Fungal isolates } \\
\hline & $\begin{array}{c}3 \\
0 \\
3 \\
0 \\
3 \\
2 \\
0 \\
0 \\
0 \\
0 \\
0 \\
0 \\
0\end{array}$ & 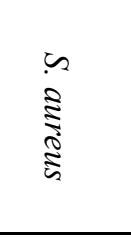 & 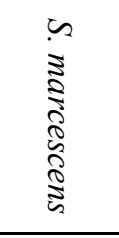 & 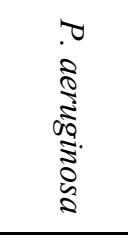 & 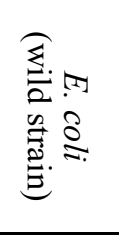 & 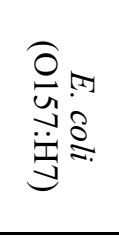 & $\begin{array}{l}\Omega \\
\vdots \\
\vdots \\
\vdots \\
\vdots \\
\vdots \\
2\end{array}$ & 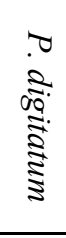 \\
\hline HLE & 125 & 62.5 & 250 & 62.5 & 62.5 & 500 & $<31.25$ & $\mathrm{~N} / \mathrm{T}$ \\
\hline CLE & $>1000$ & 250 & 62.5 & 125 & $<31.25$ & 62.5 & 250 & $\mathrm{~N} / \mathrm{T}$ \\
\hline ELE & 250 & $>1000$ & 500 & $<31.5$ & $<31.25$ & 250 & $<31.25$ & $\mathrm{~N} / \mathrm{T}$ \\
\hline MLE & 500 & $>1000$ & 250 & 250 & $<31.25$ & $<31.25$ & 250 & $\mathrm{~N} / \mathrm{T}$ \\
\hline HSB & 62.5 & 500 & 125 & 62.5 & 62.5 & 250 & $<31.25$ & $\mathrm{~N} / \mathrm{T}$ \\
\hline CSB & 62.5 & 250 & 250 & $<31.25$ & 500 & 500 & 125 & $\mathrm{~N} / \mathrm{T}$ \\
\hline ESB & $>1000$ & 125 & 125 & $<31.25$ & 500 & 250 & 250 & $\mathrm{~N} / \mathrm{T}$ \\
\hline MSB & 62.5 & 500 & 125 & 500 & 250 & 250 & 500 & $\mathrm{~N} / \mathrm{T}$ \\
\hline CRT & 250 & 500 & $<31.25$ & $<31.25$ & 125 & 125 & 500 & $\mathrm{~N} / \mathrm{T}$ \\
\hline MRT & $<31.25$ & 125 & $<31.25$ & 62.5 & $>1000$ & 500 & 250 & $\mathrm{~N} / \mathrm{T}$ \\
\hline
\end{tabular}

Refer to the footnote of Table 1. 
study, since these three microorganisms have never been used previously to screen the antimicrobial activity of any of the extracts from $U$. urens.

In a previous report, the ethanolic extract from leaves of $U$. urens collected from Tunisia showed remarkable antibacterial activity against $S$. aureus and $P$. aeruginosa with minimum bactericidal concentration/ minimum inhibition concentration (MBC/MIC) value of $2.0 \mu \mathrm{g} / \mathrm{mL}$ at a concentration of $150 \mu \mathrm{g} / \mathrm{mL}$ (Mzid et al., 2017). However, this ethanolic leaf extract did not exhibit any visible zone of inhibition against $E$. coli in the same study (Mzid et al., 2017). Again, in the same study, the water extract did not exhibit any visible zone of inhibition against $P$. aeruginosa and $S$. aureus. In another report, the chloroform and aqueous extracts from leaves of $U$. urens collected in Eritrea showed no inhibitory effect against E. coli, S. aureus and $C$. albicans (Kaushik et al., 2015). However, in our study, the chloroform leaf extract exhibited weak activity against $E$. coli and $S$. aureus with inhibition zones of $12.0 \pm 1.4$ and $10.5 \pm 2.1 \mathrm{~mm}$, respectively and a moderate activity against $C$. albicans with an inhibition zone of $17.0 \pm 4.2 \mathrm{~mm}$. In another report, the chloroform and aqueous leaf extracts of $U$. urens collected from Tunisia exhibited no zone of inhibition against $S$. aureus, E. coli and $P$. aeruginosa (Barkaoui et al., 2017). The chloroform extract and these three microorganisms were common to our study also. However, in our study, the chloroform leaves extract showed a moderate activity with inhibition zones of $12.0 \pm 1.4,10.5 \pm 2.1$ and $18.0 \pm 2.8$ $\mathrm{mm}$, respectively, against $E$. coli, $S$. aureus and $P$. aeruginosa. This discrepancy may be due to change in chemical constituents and/or their relative proportions of plant materials since they were collected at different locations. Additionally, the seasonal variations will have a prominent role in determining the chemical constituents and/or their relative proportions and subsequently the antimicrobial activities.

\section{Conclusion}

The antibacterial and antifungal activities of extracts from various parts of $U$. urens collected from the Kingdom of Lesotho, Southern Africa were evaluated. These extracts exhibited inhibition zones in the range of $9.0 \pm 0.0$ to $40.5 \pm 0.7 \mathrm{~mm}$ against bacterial isolates and $16.0 \pm 4.2$ to $17.5 \pm 4.9 \mathrm{~mm}$ against C. albicans. However, all these extracts exhibited no zone of inhibition against $P$. digitatum. Furthermore, the minimum inhibitory concentrations (MICs) of various extracts of $U$. urens were evaluated. The MIC values of these extracts were found to be in the range of $<31.25$ to $>1000 \mu \mathrm{g} / \mathrm{mL}$, against both the bacterial and fungal isolates. From this study, we concluded that ELS, MLE, CRT and MRT showed promising antimicrobial activities.

\section{Conflict of interest}

The authors declare no conflict of interest.

\section{Acknowledgements}

The authors would like to thank the National University of Lesotho for the support. We also thank Mrs. Sesomo Phalatsi, a resident of Lithabaneng Ha Keiso village for the provision of the plant materials.

\section{References}

Alghazeer, R., El-Saltanil, H, Saleh, N., Al-Najjar, A. and Hebail, F. (2012). Antioxidant and antimicrobial properties of five medicinal Libyan plants extracts. Natural Science, 4, 324-335. https:// doi.org/10.4236/ns.2012.45045

Alghazeer, R., Elmansori, A., Sidati, M. and Gammoudi, F. (2017). In vitro antibacterial of flavonoid extracts of two selected Libyan Algae against multi-drug resistant bacteria isolated from food products. Journal of Biosciences and Medicine, 5, 26-48. https://doi.org/10.4236/jbm.2017.51003

Barkaoui, T., Kacem, R., Guesmi, F., Blell, A. and Landoulsi, A. (2017). Evaluation of antibacterial and antioxidant properties of Urtica urens extract tested by experimental animals. International Journal of Pharmacology, 13(3), 332-339. https:// doi.org/10.3923/ijp.2017.332.339

Coleman, M., Kristiansten, P., Sindel, B. and Fyfe, C. (2018). Dwarf nettle (Urtica urens). Weed management guide for Australian vegetable production. Armidale, Australia: University of New England.

Daud, A., Gallo, A. and Anchez, A. (2005). Antibacterial properties of Phrygilanthus acutifolius. Journal of Ethnopharmacology, 99(2), 193-195. https:// doi.org/10.1016/j.jep.2005.01.043

Emmanuel, M.T., Anatole, C.P. and Veronique, P.B. (2012). Investigations of antimicrobial activity of some Cameroonian medicinal plant extracts against bacteria and yeast with gastrointestinal relevance. Journal of Ethnopharmacology, 142(1), 265-273. https://doi.org/10.1016/j.jep.2012.05.005

El-Seadawy, H.M., Abo El-Seoud, K.A., Kabbash, A.M., El-Aasr, M. and Attia, G.I. (2018). Phytochemical and biological investigation of Urtica urens growing in Egypt. International Research of Pharmacy, 9(1), 25-35. https://doi.org/10.7897/2230-8407.0915

Kaushik, A., Aron, A., Mihreteab, S., Mohamedksasm, N. and Kidane, E.M. (2015). Phytochemical 
screening of medicinal plants used by Eritrean traditional healers. World Journal of Pharmaceutical Research, 4(4), 501-509.

Kregiel, D., Pawlikowska, E. and Antolak, H. (2018). Urtica spp.: Ordinary plants with extraordinary properties. Molecules, 23(7), 1664. https:// doi.org/10.3390/molecules23071664

Lati, R.N., Shem-Tov, S. and Fennimore, S.A. (2016). Burning nettle (Urtica urens) Germination and seed bank characteristics in coastal California. Weed Science, 64(4), 664-672. https://doi.org/10.1614/WSD-15-00205.1

Manilal, A., Sujith, S., Kiran, G.S., Seivin, J., Shakir, C., Gandhimathi, R. and Panokkar, M.V.N. (2009). Biopotentials of seaweeds collected from southwest coast of India. Journal of Marine Science and Technology, 17, 67-73.

Matela, K.S., Pillai, M.K. and Mekbib, S.B. (2018). Antimicrobial activities of extracts from Gleditsia triacanthos L. and Schinus molle L. Pharmacologyonline, 2, 85-92.

Moteetee, A. and Kose, L.S. (2017). A review of medicinal plants used by Basotho for treatment of skin disorders: their phytochemical, antimicrobial and anti-inflammatory potential. African. Journal of Complementary Alternative Medicine, 14(5), 121137. https://doi.org/10.21010/ajtcam.v14i5.16

Moteetee, A. and Van Wyk, B.E. (2011). The medical ethnobotany of Lesotho: a review. Bothalia, 41(1), 209-228. https://doi.org/10.4102/abc.v41i1.52

Mzid, M., Ben Khedir, M., Ben Salem, M., Regaieg, W. and Rebai, T. (2017). Antioxidant and antimicrobial activity of ethanol and aqueous extracts from Urtica urens. Pharmaceutical Biology, 55(1), 775-781. https://doi.org/10.1080/13880209.2016.1275025

Nencu, I., Vlase, L., Istudor, V., Mircea, T. (2015). Preliminary research regarding Urtica urens L. and Urtica dioca L. Farmacia, 63(5), 710-715.

Njimoh, D.L., Assob, J.C.N., Mokake, S.E., Nyhalah, D.J., Yinda, C.K. and Sandjon, B. (2015). Antimicrobial activities of a plethora of medicinal plant extracts and hydrolates against human pathogens and their potential to reverse antibiotic resistance. International Journal of Microbiology, 2015, 547156. https://doi.org/10.1155/2015/547156

Schellman, A.E. and Shrestha, A. (2008). Burning and Stinging nettles. Integrated Pest Management for Home Gardeners and Landscape Professionals. USA: University of California. 